\title{
Addressing Racial Disparities in Mental Health for African American Males
}

\author{
Nathalie Mizelle, Ph.D ${ }^{1 *}$, James Maiden, Ed.D ${ }^{1}$, Delarious O. Stewart, Ed.D ${ }^{2}$ \\ ${ }^{I}$ Associate Professor of Counseling University of the District of Columbia 4250 Connecticut Ave Washington, \\ DC 20002, USA \\ ${ }^{2}$ Manager of School Psychology District of Columbia Public Schools 3535 V St., NE, Washington, DC 20018, \\ USA
}

*Corresponding Author: Nathalie Mizelle, Ph.D, Associate Professor of Counseling University of the District of Columbia 4250 Connecticut Ave Washington, DC 20002, USA

\begin{abstract}
Good mental health is a contributing factor to increased life expectancy and fewer physical health concerns, but poor mental health can be a catalyst to declining health and an early death. Unfortunately, there are racial disparities in mental outcomes, treatment, and resources. These disparities have trickling consequences on how the rest of society operates. The article discussed the racial disparities in mental health and the obstacles that have historically prevented African American males from seeking mental health counseling. Recommendations are provided for counselors and other mental health professionals to combat the problem.
\end{abstract}

Key words: Racial Disparities, African American, Mental Health, Black men

\section{INTRODUCTION}

Mental illness affects millions of individuals in the United States but unfortunately affects African Americans, specifically, African American males more drastically than others. With the murders of Ahmud Aubrey and George Floyd, and Black Live Matters protest on police brutality on Black men (Maiden, Mizelle, Nichols, \& Stewart, 2020), mental health has been given more consideration in regard to its effect on not just physical health but an individual's overall well-being. Additionally, the corona virus (COVID-19) pandemic effect on communities of color has given more attention and respect to African Americans' need for mental health care. Both events have exposed deep-seated inequalities in mental health care for African Americans and magnifies social and economic issues contributing to poor health outcomes, compounding longstanding racial disparities. This commentary aims to explore the racial disparities in mental health for African American males and provide recommendations for counselors/therapists and other mental health professionals to combat the problem.

\section{LITERATURE REVIEW}

Although racial disparities exist in all areas of treatment and healthcare, mental health is an area that should not go overlooked. There are apparent disparities between African American males and their White counterparts concerning mental health and their willingness to seek treatment. Despite research indicating that African Americans struggle with mental illness and may deal with more persistent mental health issues than Caucasians, African Americans, specifically Black males, seek mental health treatment at lower rates than Caucasians (Buser, 2009). African American males also have lower treatment retention rates in mental health services than Caucasian males (Cruz, Pincus, Harman, Reynolds, \& Post, 2008). Societal factors influence health beliefs and behaviors positively and negatively. Some of these factors function as barriers to seek mental health treatment, while others act as motivators (Plowden, 2003). African American families are more likely to report a lack of financial resources (insurance coverage, cash) than Caucasian families (Cheat man, Barksdale \& Rodgers, 2008). This is extremely important because individuals who lack such resources encounter great difficulty accessing mental health care (Cheat man, Barksdale \& Rodgers, 2008). As a result of the 
disparities in availability and quality of mental health care services for African Americans, they "bear a disproportionately high disability burden from mental health disorders" (Allen, Davey \& Davey, 2010). The differences are not just exclusive to adults; African American children and adolescents are more likely than Caucasians to have unmet needs for mental health services (Cummings, Ponce, \& Mays, 2010). African American males' mental health needs remain largely unmet (Chow, Jaffee \& Snowden, 2003).

\section{CAUSES OF RACIAL Disparity}

The disparities that exist are not a phenomenon that randomly happened, but instead, they are byproducts of a system of events, circumstances, and variables consistently interacting. There are three significant barriers to health care that affect all Americans, including lack of health insurance, lack of a usual source of care, and perception of need (Cheat man, Barksdale \& Rodgers, 2008). When these factors are missing or neglected, health is affected. Unfortunately, these factors are being neglected more in African American communities (Plowden, 2003). These factors and others are responsible for the racial disparity in mental health treatment and the seeking of mental health. Often, the disparity in mental health seeking and treatment has been attributed to alternative coping strategies and African Americans' attitudes towards services (Buser, 2009). Alternative coping mechanisms/resources used in African American communities can be why some are hesitant to seek mental health treatment. These personal and cultural coping resources may serve as substitutes for professional mental health assistance and affirm social norms about such service's irrelevance. African Americans tend to rely heavily on family and friends' encouragement rather than directly asking for assistance from professionals. Another alternative resource in which African Americans use is religious leaders. Research has found that African Americans report seeking assistance for personal problems from religious leaders to a higher degree than mental health professionals. Similar research found that African American churches provided more mental health services than Caucasian churches. This affects those individuals that seek mental health treatment because individuals who initially sought assistance from clergy for issues/concerns were less likely to seek mental health service (Buser, 2009).

One must consider the cultural impact when discussing the attitudes that African Americans have related to mental health services. There is often a stigma associated with mental illness, but this is especially true in the African American community. African Americans have shown to hold more negative attitudes towards mental health and mentally ill than Caucasians (Cruz et al., 2008). According to a Surgeon General's report, stigma has been recently highlighted as a major barrier to receiving mental health treatment (Strauser, Ciftci\& O'Sullivan, 2009). In the African American community, stigma in the family and community plays a role in dissuading African Americans from seeking mental health care (Buser, 2009). Individuals are fearful of the consequences of being associated with mental health treatment or mental illness. Research has shown that employers are less likely to hire individuals with a known mental illness, and landlords are less likely to lease to individuals for the same reason (Strauser, Ciftci\& O'Sullivan, 2009). Buser (2009) confirmed that African Americans identified embarrassment, disgrace, and isolation as things associated with mental illness and seeking mental health treatment.

When considering African Americans' attitudes towards the mental health system, it is vital to include the cultural mistrust present. The mistrust of health care providers is extremely influential to African Americans seeking mental health care. The "Tuskegee Study of Untreated Syphilis in the Negro Male" has had a lasting impact on the African American community (Buser, 2009). From this study, some African Americans have developed a generalized suspicion or mistrust of institutions that are primarily Caucasian Americans such as mental health services (Duncan, 2003). Research has shown some African Americans believe that the Tuskegee experiment/study is still representative of current medical research. This mistrust holds, especially when African Americans are being treated by Caucasian professionals (Buser, 2009). In addition to the Tuskegee experiment, African Americans may have negative attitudes towards seeking medical care, which can explain their mistrust of Caucasian clinicians and subsequently lower mental health services, especially in times of need (Diala, Muntaner, Walrath, Nickerson \&LaVeist, 2001). African Americans who were more mistrusting of clinicians were more likely to terminate from therapy prematurely, had lower, and more negative expectations of their counseling encounter with Caucasians clinicians and perceived these clinicians as a less credible source of help (Duncan, 2003). Previous literature indicates differences in 
diagnosis and prescription patterns, which may have also contributed to the mistrust African Americans have towards the mental health system. There has been evidence that African Americans are more likely to be diagnosed with schizophrenia and paranoid personality disorder than Caucasians (Maiden, Mizelle, Nichols, \& Stewart, 2020). In these findings, it has been noted that Caucasian clinicians exhibited this pattern to a greater degree. Racial bias may be a part of these diagnosis differences, and clinicians may hold racial stereotypes about mental illness (Buser, 2009). Provider bias in treating mental disorders has long been a deterrent for African Americans and their tendency to seek care (Diala et al., 2001). The issue of biased care can be an explanation for the different prescription and diagnostic rates. Studies have shown that African American clients were less likely to be prescribed atypical antipsychotics, which are believed to produce more beneficial effects, and were more likely to be given earlier-generation depot antipsychotics (Buser, 2009).

The differences in diagnostic and prescription practices suggest a racial bias in the mental health care system. This racial bias can be described as micro aggressions (Sue et al., 2007), which is defined as "brief and commonplace daily verbal, behavioral, and environment indignities, whether intentional or unintentional, that communicate hostile, derogatory or negative racial slights and insults to the target person or group." These micro aggressions are present in diagnostic and prescription practices and in therapy sessions but are likely to go undetected by the clinicians. Micro aggressions in which African Americans often experience include counselors avoiding discussion of cultural issues in session, denying the harboring of racial biases, accusing the client of being too sensitive about racial issues, being unaware of racial issues, communicating racial stereotypes and using culturally inappropriate therapeutic assistance. Such experiences have psychological consequences: feelings of powerlessness, a sacrifice of personal integrity to meet Caucasian standards, a sense of invisibility, and feeling a sense of force to represent one's racial group (Sue et al., 2007). Micro aggressions lead to the weaker therapeutic alliance and are a strong predictor of adverse mental health outcomes. The treatmentseeking disparity is often explained by emphasizing attitudes toward mental health service, resources in the African American community, and forms of racial bias in mental health care (Buser, 2009). With these contributors consistently working against African American males, it is obvious why they are not readily seeking mental health treatment. Whether unintentional or subtle, racial bias or racism present in mental health treatment has contributed to the entire system's cultural mistrust.

\section{African American Males and Mental Health}

African American males make up approximately 6\% of the general population; however, they make up a significantly higher percentage of those with chronic illness, physical and mental (Plowden, 2003). The average life expectancy of African American males in the United States is 69 years of age, six years less than that of their Caucasian counterparts. Although these cannot solely contribute to mental health concerns and lack of treatment, it should be considered part of the equation (Cheatham, Barksdale, \& Rodgers, 2008). African American males have historically underutilized available mental health treatment and services (Duncan, 2003). As a result of this neglect, African American males in America are disproportionately affected by adverse mental health outcomes (Cheatman, Barksdale \& Rodgers, 2008). In comparison to African American females, Caucasian males, and Caucasian females, African American males are overrepresented in mental hospitals (Duncan, 2003).

Perception is reality, and African American males perceive the mental health services in their communities are too few and of poor quality, deterring them from seeking treatment (Plowden, 2003). African American males tend to avoid treatment entirely or do not seek treatment until the condition worsens, and they require the use of emergency departments or are mandated. When receiving care under these circumstances, continuity and quality of care, risk reduction, and adequate mental illness management do not occur or are inferior (Cheatman, Barksdale \& Rodgers, 2008). There are existing obstacles specific to African American males and mental health treatment that often go overlooked. Although all barriers and circumstances cannot be accounted for or overcome, it is essential to be aware of them to promote the profession and individuals' continuing progression. Like anything else there are barriers that effect African American males relating to health care and more specifically mental health. In addition to the previously mentioned barriers that affect all Americans health care, African American males have barriers that are specific to them when referring to mental health treatment. The barriers that African Americans are challenged which include socioeconomic status and criminal background, masculinity, lack of awareness of the need for care, and racism and distrust of medical establishment. Although socioeconomic status and criminal background are things that 
everyone must overcome it is slightly enhanced for African American males. These two are highly related when discussing access to mental health care. According to statistics from the Bureau of Justice Statistics, African American males had a 32\% chance of being incarcerated in their lifetime compared to $5.9 \%$ of Caucasian males. With a criminal background it is likely to have a negative impact one's available job options, leading to unemployment or low paying jobs that are transient in nature and do not offer medical coverage. Without adequate medical coverage or socioeconomic status African American males are unable to seek mental health treatment if needed (Cheat man, Barksdale \& Rodgers, 2008).

Research has identified masculinity as a barrier to mental health-seeking behavior for African American males. Studies have shown that African American males stated that they were "supposed to handle anything (Cheat man, Barksdale \& Rodgers, 2008). Their masculinity is directly related to their lack of willingness to seek mental health treatment voluntarily. This can stem from them being socialized to handle difficulties/problems by not showing stress or suppressing the intensity of emotions (Duncan, 2003). African American males often feel an added sense of responsibility to be providers for their family and are more likely to place the care/needs of their spouses and children ahead of their mental health. In addition to placing their family's needs above their own, they often felt minimal exposure to mental illness. In studies, African American males reported that they felt as if they were tough and not at risk for mental illness (Cheat man, Barksdale \& Rodgers, 2008). In turn, this had a negative effect because they often waited until symptoms were severe and could have likely been avoided.

There is a lack of awareness of the need for mental health care by African American males, which is a potential barrier for them (Cheat man, Barksdale \& Rodgers, 2008). Perceived susceptibility is measured by an individual's belief or perception of the risk of acquiring an illness. Concerning mental illness, African American males have a low perceived susceptibility, meaning that they do not believe they are vulnerable to mental illness (Plowden, 2003). African American males are more likely to seek treatment when they cannot perform their normal daily activities. Without a historical presence of primary and preventive medical treatment in many African American households, African American males initially do not consider mental health treatment a valuable option. Research demonstrate that African American males felt that, as children, their mothers did not take them to see healthcare providers until they were seriously ill. This reinforces their current thoughts, to only seek treatment when symptoms become severe. In addition, African American males have shown and expressed uncertainty in recognizing signs and symptoms of mental illness (Cheat man, Barksdale \& Rodgers, 2008).

By far, racism and distrust is the most acknowledged barrier to mental health care and mental healthseeking behavior among African American males. In a recent study by Cheat man, Barksdale \& Rodgers (2008), 54\% of African American males' perceived race was a barrier to receiving appropriate care as opposed to $23 \%$ of Caucasians males. This perceived barrier has resulted in an overall dissatisfaction with their mental health, primary physicians, and the care in which they received. The dissatisfaction has had a trickle-down effect, resulting in less contact with healthcare providers than Whites and even African American females. This distrust of the medical system has historical significance and roots. The "Tuskegee Study of Untreated Syphilis in the Negro Male" has contributed to the African American male's mistrust of health providers. For many African American males, incidents such as the Tuskegee study serve as an affirmation that the medical system and professionals cannot be trusted. The history and legacy of discrimination with the healthcare system fuel present-day mistrust for African American males. This distrust from African American males has resulted in fewer visits to healthcare providers, more emergency room visits, and neglect towards overall mental health (Cheat man, Barksdale \& Rodgers, 2008).

For those African American males who enter therapy, outcomes are not always ideal. These males often report high levels of dissatisfaction and experience premature termination rates and low successful therapy outcomes (Maiden, Mizelle, Nichols, \& Stewart, 2020).

Clinicians who encounter African American males report that they are evasive and nonresponsive to therapeutic interventions. Many therapists have labeled this attitude as reluctant to engage in the 
therapeutic process than individuals seeking to develop alternative interventions specific to the population being served (Duncan, 2003).

\section{What CAN Be Done?}

African Americans males are a unique population to work with, and one must consider their unique cultural characteristics when working with them. The development of appropriate interventions and outreach is vital and should be dependent upon understanding critical social factors that influence health-seeking behavior (Plowden, 2003). Research has found that African Americans are more likely to seek mental health assistance from religious leaders and primary than from mental health professionals (Buser, 2009). With this knowledge, clinicians should advocate working with community churches and religious leaders, explaining the importance of mental health and appropriate mental health treatment. African American clergy have a critical role in delivering mental health care services for parishioners and their families. Their significance is evident because African Americans tend to first seek ministers' support during personal emotional distress and crises. Unfortunately, in some cases, leaders are struggling to meet their members' needs because they are without the necessary clinical skills to assess, diagnose, or treat some mental illnesses appropriately. Clinicians should not use this information to boast about their skills but instead, as motivation to build a more collaborative partnership with African American church leaders to be more effective in reaching African American males. It is in churches where messages about seeking and receiving mental health treatment can be shaped by the influential interpersonal social interactions (Allen, Davey \& Davey, 2010).

Duncan postulated that some African Americans seeking to utilize mental health treatment prefer an African American counselor. There needs to be work done to assist in removing the stigma associated with mental health treatment. Two approaches that can help reduce the stigmatizing of mental health treatment and illness are education and contact. Education strategies are aimed to dispel commonly help myths regarding mental illness and treatment by presenting information. The goal should be to not only educate clients but the clinicians and community.

The other approach is interpersonal contact, which can produce the most considerable improvement in perception. This approach aims to have individuals increase the amount of positive time spent with individuals who are stigmatized. The increased positive time is expected to decrease the negative stigmas associated with the individual. Clinicians should be proactively working against public and self-stigma for individuals with mental illness and receiving mental health treatment (Strauser, Ciftci\& O’Sullivan, 2009).

Clinicians should actively dialogue with patients about perceived barriers and tailor treatment to overcome those (Cruz et al., 2008). Outside of the medical sector, the school has been identified as the most critical setting to deliver mental health services and minimize racial disparities. This is because of the potential to overcome barriers such as cost, transportation, and stigma associated with services in clinical settings (Cummings, Ponce, \& Mays, 2010). Counselors need to commit to a multicultural counseling competency that includes awareness of the racism present in mental health treatment (Buser, 2009).

\section{RECOMMENDATIONS AND CONCLUSION}

The lack of a clear understanding of factors that influence African American males' participation in therapeutic venues continues to impede any sustained momentum in encouraging African Americans males to utilize formal counseling (Duncan, 2003). Improving mental health status and care of African American males will require motivation, effort, and awareness, diligence and creativity among providers and system-wide changes within the mental health establishment (Cheat man, Barksdale \& Rodgers, 2008). With African American males, clinicians and others can do several things to encourage mental health treatment and treatment-seeking behavior. Trust is needed to improve African American males' treatment-seeking behavior with mental health concerns (Plowden, 2003). Trust is likely the most crucial catalyst needed to encourage African American males to seek mental health treatment (Maiden, Mizelle, Nichols, \& Stewart, 2020).

When addressing the African American male population, it must start with awareness being raised among the males, the African American community, and clinicians. This awareness must educate African American males that they are not seeking mental health treatment when needed, and it is 
having detrimental effects on their overall health (Cheat man, Barksdale \& Rodgers, 2008). Aside from the males themselves, awareness must be raised in the community. African American males are more likely to seek treatment if a female family member suggested it. This is perceived to be true because males believe them to be trustworthy and concerned about their overall well-being. Knowing this, therapists should look to use these family members as facilitators for treatment when working with African American men (Cheat man, Barksdale \& Rodgers, 2008). In addition to raising awareness, the male community leaders can look to restructure the definition of African American masculinity. Male community leaders can reframe the definition from a man too strong to seek mental health treatment to a man taking charge of his overall health (Cheat man, Barksdale \& Rodgers, 2008). Many government-subsidized programs are tailored towards children, persons with disabilities, elderly and pregnant women. Although it may not be the most popular thing to hear, it should be considered to include African American males because of the overwhelming evidence that they are often unable to afford health care and disproportionally affected by mental illnesses (Cheat man, Barksdale \& Rodgers, 2008). Motivators of treatment-seeking behavior for African American males are heavily influenced by societal factors (Plowden, 2003). Conducting outreach programs convenient to this population can also promote increased mental health participation (Cheat man, Barksdale \& Rodgers, 2008).

African American males have been shown to highly value providers that are perceived as caring in nature. They often measure this caring nature by assessing body language, vocal tone, sitting on the patient's level, conducting sessions in an unhurried manner, and making consistent eye contact (Cheat man, Barksdale \& Rodgers, 2008). Also, African American males appreciated those providers who considered social issues when conducting sessions (Cheat man, Barksdale \& Rodgers, 2008).

There is limited research that addresses the specific attitudes and willingness of African American males to seek mental health treatment (Duncan, 2003). For the counseling profession to be effective at reaching this population, research must be conducted, interventions developed, awareness increased, and effort maximized. Mental health service providers are going to have to do a better job of distinguishing themselves from those institutions seen as oppressive and hostile be African American males. These institutions must also do a better job training counselors to work with African American males and the unique issues they bring into the therapeutic relationship.

\section{REFERENCES}

[1] Allen, A. J., Davey, M. P., \& Davey, A. (2010). Being examples to the flock: The role of church leaders and African American families seeking mental health care services. Contemporary Family Therapy: An International Journal, 32(2), 117-134.

[2] Buser, J. K. (2009). Treatment-seeking disparity between African Americans and whites: Attitudes toward treatment, coping resources, and racism. Journal of Multicultural Counseling \& Development, 37(2), 94-104.

[3] Cheatham, C. T., Barksdale, D. J., \& Rodgers, S. G. (2008). Barriers to health care and health-seeking behaviors faced by black men. Journal of the American Academy of Nurse Practitioners, 20(11), 555-562.

[4] Chow, J. C., Jaffee, K., \& Snowden, L. (2003). Racial/Ethnic disparities in the use of mental health services in poverty areas. American Journal of Public Health, 93 (5), 792-797.

[5] Cruz, M., Pincus, H. A., Harman, J. S., Reynolds, CF,,III, \& Post, E. P. (2008). Barriers to care-seeking for depressed Africanamericans. International Journal of Psychiatry in Medicine, 38(1), 71-80.

[6] Cummings, J. R., Ponce, N. A., \& Mays, V. M. (2010). Comparing racial/ethnic differences in mental health service use among high-need subpopulations across clinical and school-based settings. Journal of Adolescent Health, 46(6), 603-606.

[7] Diala, C.C., Muntaner, C., Walrath, C., Nickerson, K., \&LaVeist, T. (2001). Racial/Ethnic differences in attitudes toward seeking professional mental health services. American Journal of Public Health, 91 (5) 805-807.

[8] Duncan, L. E., (2003). Black male College Students' Attitudes Toward Seeking Psychological Help. Journal of Black Psychology, 29(68) 65-85.

[9] Maiden, J. L., Mizelle, N., Nichols, B.J., \& Stewart, D.O.(2020). The impact of micro aggressions on men of color in graduate counseling programs. International Journal of Social Policy and Education, 2 (5).

[10] Plowden, K. O. (2003). A theoretical approach to understanding black men's health-seeking behavior. Journal of Theory Construction \& Testing, 7(1), 27-31.

[11] Strauser, D.R., Ciftci, A., \& O'Sullivan, D. (2009). Using attribution theory to examine community rehabilitation provider stigma. International Journal of Rehabilitation Research. 32 (1), 41-47. 
[12] Sue, D.W., Capodilupo, C.M., Torino, G.C., Bucceri, J.M., Holder, A.M.B., Nadal, K.L., \& Esquilin, M. (2007). Racial micro aggressions in everyday life: Implications for clinical practice. American Psychologist, 62, 271-286. doi: 10.1037/0003-066X.62.4.271

\section{AUTHORS' BIOGRAPHY}

Dr. Nathalie Mizelle, is an Associate Professor of Counseling at the University of the District of Columbia.

Dr. James Maiden, is an Assistant Professor of Counseling at the University of the District of Columbia.

Dr. Delarious O. Stewart, is the Manager of School Psychology at the District of Columbia Public Schools.

Citation: Nathalie Mizelle, Ph.D, et.al. "Addressing Racial Disparities in Mental Health for African American Males" International Journal of Humanities Social Sciences and Education (IJHSSE), vol 7, no. 7, 2020, pp. 199-205. doi: https://doi.org/10.20431/2349-0381.0707022.

Copyright: (C) 2020 Authors. This is an open-access article distributed under the terms of the Creative Commons Attribution License, which permits unrestricted use, distribution, and reproduction in any medium, provided the original author and source are credited. 